\title{
Hydraulic Investigation of Piano Key Weir
}

\author{
Le Anh Tuan ${ }^{1 *}$ and Ken Hiramatsu ${ }^{2}$ \\ ${ }^{1}$ The United Graduate School of Agricultural Science, Gifu University, Tokai National Higher Education and \\ Research System, Gifu 501-1193, Japan \\ ${ }^{2}$ Faculty of Applied Biological Sciences, Gifu University, Tokai National Higher Education and Research System, \\ Gifu 501-1193, Japan
}

\begin{abstract}
Piano Key weir is a modified labyrinth weir that uses cantilevered up- and downstream overhangs in order to restrict its basis length. The small footprint on foundation of Piano Key weirs allows an easier placement on the crest of the existing dams such as concrete gravity dams and arch dams. The recent studies have shown that this new type of weir can provide more than four times as much discharge capacity as a traditional ogee-crested weir can at a defined hydraulic head and a constant width occupied by the structure on the dam. However, until now, there is not yet an empirical method that considered all of the published experimental data due to its geometric complexity. The aim of this present paper is to summarize the most pertinent information on Piano Key weir hydraulics in the preceding articles in order to provide a better understanding of how this innovative weir type operates and what the future researches which warrant further investigation are.
\end{abstract}

\section{Keywords}

discharge capacity; hydraulic design; labyrinth weirs; piano key weir

\section{Introduction}

Global warming is predicted to amplify the rainfall intensity due to the increases in evaporation from soil and storage capacity of moisture in atmosphere. Though the total annual precipitation has not changed significantly for several decades, the intensity of storms is likely to be more severe (Trenberth, 2011). According to Mei and Xie (2016), typhoons that struck East and Southeast Asia have intensified by 12 to 15 percent over the past 37 years. It is predicted that the ocean warming suggests that typhoons striking Japan, as well as eastern China, Taiwan, and the Korean Peninsula, will intensify further in the subsequent years. This might cause an embankment collapse of outdated small reservoirs, such as irrigation ponds due to insufficient discharge capacity of spillways. For example, in Southwestern Japan, torrential rain with return period more than 200 years in July 2018 caused a severe damage to several irrigation ponds, some of which were completely destroyed. With the different available numerical climate models and the development of new methodologies for analysis of climatic and hydrologic data, as well as higher requirements of the communities on safety management standard, a large number of existing dams necessitate improvement or rehabilitation of spillways in order to remove the excess flow from hydro system and prevent overtopping. To give in to these demands, Piano Key weir (PK weir) was developed. This type of spillway, which is a further development of labyrinth weir, was first initiated by Hydrocoop in collaboration with Biskra University (Algeria), the Hydraulic Laboratory of Elictricité de France (France) and Roorkee University (India) (Lempérière and Ouamane, 2003). It uses cantilevered apexes to restrict its basis length (Blanc and Lempérière, 2001) and permits its installation on top of existing structures such as concrete gravity dams and arch dams (Barcouda et al., 2006) and

Received September 9, 2020, Revised October 11, 2020, Accepted October 16, 2020

Published online: November 29, 2020. *Correspondence to LA.T.: latuan@tlu.edu.vn 
internal ramps in the cycles, thus reducing the forces exerting on the lateral walls and hence the structural cost (Paxson et al., 2013). The recent studies have shown that this weir can provide more than four times as much discharge capacity as a traditional ogee-crested weir can at a defined hydraulic head and a constant width occupied by the structure on the dam (Ouamane and Lempérière, 2006).

Table 1: The world register of PK weirs

\begin{tabular}{|c|c|c|}
\hline Dam name & Country & Completion year \\
\hline Bakkhada & Algeria & 1938 \\
\hline Beni Bahdel & Algeria & 1940 \\
\hline Goulours & France & 2006 \\
\hline Saint-Marc & France & 2008 \\
\hline Etroit & France & 2009 \\
\hline Gloriettes & France & 2010 \\
\hline Rattling Lake & Canada & 2011 \\
\hline Escouloubre & France & 2011 \\
\hline Gouillet & France & 2011 \\
\hline Malarce & France & 2012 \\
\hline Beaufort & France & 2013 \\
\hline Black Esk & United Kingdom & 2013 \\
\hline Dak Mi 4B & Vietnam & 2013 \\
\hline Dak Rong 3 & Vietnam & 2013 \\
\hline Giritale & Sri Lanka & 2013 \\
\hline Loombah & Australia & 2013 \\
\hline Sawra Kuddu & India & 2013 \\
\hline Emma & Switzerland & 2013 \\
\hline Campauleil & France & 2014 \\
\hline Charmines & France & 2015 \\
\hline Rambawa Tank & Sri Lanka & 2015 \\
\hline Rassisse & France & 2015 \\
\hline Raviege & France & 2015 \\
\hline Van Phong & Vietnam & 2015 \\
\hline Da Dang 3 & Vietnam & 2016 \\
\hline Dak Mi 3 & Vietnam & 2016 \\
\hline Record & France & 2016 \\
\hline Xuan Minh & Vietnam & 2016 \\
\hline Gage & France & 2017 \\
\hline Hazelmere & South Africa & 2017 \\
\hline Oule & France & 2018 \\
\hline Ouljet Mellegue & Algeria & 2018 \\
\hline Lewis Creek reservoir & USA & 2019 \\
\hline
\end{tabular}

Over the last decades, many studies have been carried out in more than 15 institutions in order to comprehend the hydraulic behaviors of PK weir, the influences of several geometrical parameters on PK weir discharge efficiency (Anderson and Tullis, 2012; Erpicum et al., 2010; Ho Ta Khanh et al., 2011; Laugier, 2007; Leite Ribeiro et al., 2012a). More than 30 PK weirs are in operation or under construction in France (Laugier, 2007; Laugier et al., 2009), Vietnam (Ho Ta Khanh et al., 2011, 2012), Sri Lanka (Jayatillake and Perera, 2013), Switzerland (Eichenberger, 2013) and Scotland (Ackers, 2013) with more than two-thirds associated with dam rehabilitations 
(increase in spillway capacity). Some PK weirs are multipurpose schemes with irrigation and hydro features (Dakmi 2 and Van Phong barrage, Vietnam). Van Phong barrage is so far the longest PK weir (475 m), with the largest capacity $\left(14,400 \mathrm{~m}^{3} / \mathrm{s}\right)$, in the world. On the left bank is located the intake with the irrigation channel and on the right is located the powerhouse with 2 units. The water through the 2 turbines can be collected downstream by a small weir to irrigate the lowest area near the coast (Ho Ta Khanh, 2017). The World Register of Piano Key Weirs (https://www.uee.uliege.be/cms/c_5026433/en/world-register-of-piano-key-weirs-prototypes), which is mentioned in Table 1, aims at gathering all PK weir projects. Two Algerian labyrinth spillways have also been added in the register as they are similar to the PK weir concept. Some other projects are also being studied in the USA (Crookston et al., 2016).

Although several PK weir projects have been completed and many researchers have published their own studies on PK weir discharge efficiency, there is not yet an empirical method that considered all of the published experimental data. Their hydraulic design procedures were usually based on similarity laws to scale up from physical model to field-size situation. Boillat et al. (2011) highlights the need for the creation of an experimental database about PK weir. One of the challenges related to PK weir design is the great number of geometric parameters involved (Bieri et al., 2009; Laugier, 2007; Laugier et al., 2009). Hence, to synthesize information from various sources, most of which were published in three conference proceedings (Erpicum et al., 2011, 2013, 2017b), this paper presented a succinct review of PK weir hydraulic design procedure and addressed some future prospect of research.

\section{Background}

The geometric specificities of the PK weir include a large set of parameters. The PK weir-unit can be defined as the fundamental structure of a PK weir, comprised of two lateral walls, an inlet and two half outlets located on each side of the inlet (Figure 1). The key geometric parameters are weir height $P$, the number of PK weir-units $N_{u}$, lateral crest length $B$, in- and outlet widths $W_{i}$ and $W_{o}$, up- and downstream overhang lengths $B_{o}$ and $B_{i}$ and the wall thickness $T_{s}$ (Pralong et al., 2011). $i$; $o$ and $s$ subscripts refer to the inlet key, i.e. the key that is filled with water for a reservoir level at the PK weir crest elevation; the outlet key, i.e. the dry key for the same reservoir level and the lateral wall, respectively.

The width of a unit $W_{u}$ is equal to $W_{i}+W_{o}+2 T_{s}$ and the total width $W$ of the weir is equal to $N_{u} W_{u}$. The developed crest length $L_{u}$ of a unit is equal to $W_{u}+2 B$ and the total crest length $L$ of the weir is equal to $N_{u} L u$.

The efficiency of a PK weir can be also affected by other parameters of secondary importance, as the shape of entry under the upstream overhangs (i.e., adding "noses"), the section of the crest (i.e., elevating the crest via a parapet wall), crest shape profiles (i.e., flat-topped, half-rounded, upstream quarter-rounded and downstream quarter-rounded) (Cicero and Delisle, 2013).

Basic geometry of a PK weir, called type A, includes symmetrical overhangs. When the downstream or the upstream overhang is omitted, the PK weir is of type B or C, respectively. A PK weir without overhangs, i.e. a rectangular labyrinth weir with ramped floors, is called type D (Figure 2) (Hien et al., 2006; Lempérière, 2011; Machiels et al., 2014). 


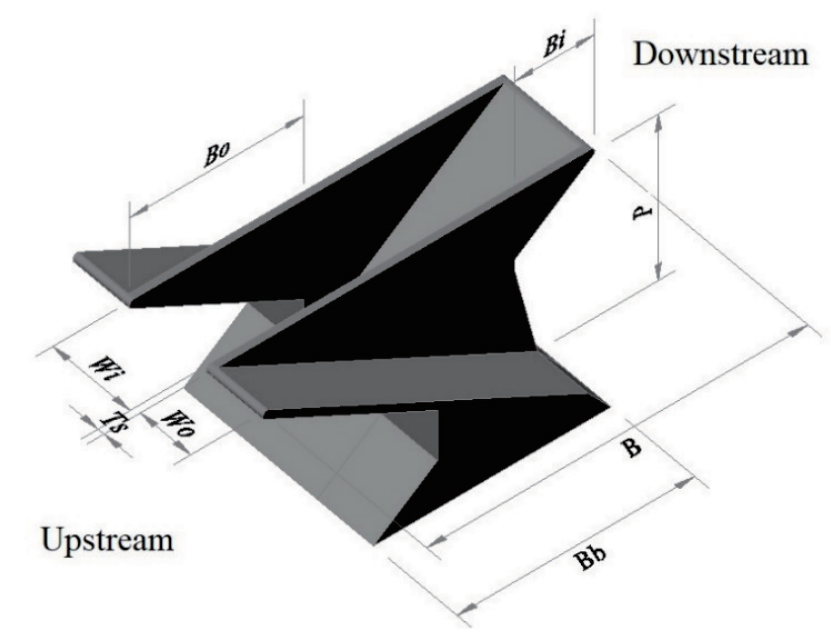

Figure 1: PK weir unit and main geometric notation

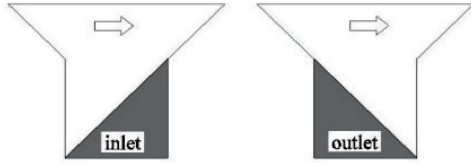

Type A

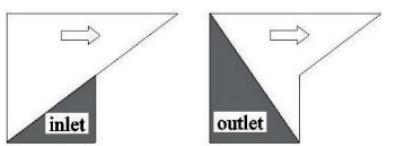

Type C

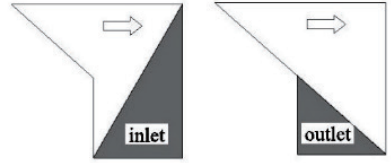

Type B

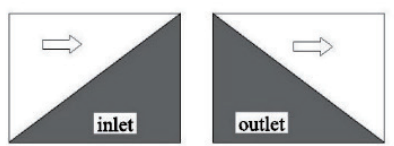

Type D

Figure 2: Different types of PK weir

\section{PK weir flow description}

Machiels et al. (2011) showed that the flow over a PK weir is the cumulative of three different types of overflow: flow over the inlet key downstream crest, flow over the outlet key upstream crest and flow over the lateral wall. Indeed, for low heads $(H / P \leq 0.2)$, where $H$ is the water head, $P$ is height of weir, the streamlines of the threedimensional flow field of a PK weir indicates that the flow approaching the inlet key remains straight as it comes into the key and then is forced upward by the ramped floor. Flow approaching the outlet key, by contrast, diverges to both sides at the centerline of the outlet key toward the inlet keys. Thus, the downstream crest of the inlet is always supplied by the current along the slopes. Meanwhile, only the surface current comes into the outlet. On the lateral crest, because of flow inertia downstream, the discharge over lateral crest in its downstream part is contributed by the partial flow in front of the inlet key and in its upstream portion by the current coming front of the outlet, under the crest level (Machiels et al., 2011) (Figure 3a). For low heads, the whole weir crest flow is of free outflow, and the water nappes flowing through the adjacent lateral crests enter the outlet key without interfering each other, which will help evacuate water out of the outlet key. Therefore the volume flow rate of the PK weir is relatively high. 
For high heads $(H / P \geq 0.2)$, as highlighted by Machiels et al. (2011) and Denys et al. (2017), the streamlines over the PK weir are less homogeneously distributed. The downstream crest which resembles a sharp-crested inclined weir (pivot weir) is supplied by both the bottom current and the front inlet current. The upstream crest is still supplied by the surface current, in the meanwhile the lateral crest is secondarily supplied by the front outlet current, flowing under the crest level (Figure 3b). Furthermore, the nappes that overflow from the adjacent lateral crests to the outlet key collide and increase local submergence effects. The previous studies clearly demonstrated that the lateral discharge capacity decreases considerably when upstream head increases, thus reducing the discharge capacity of the PK weir.

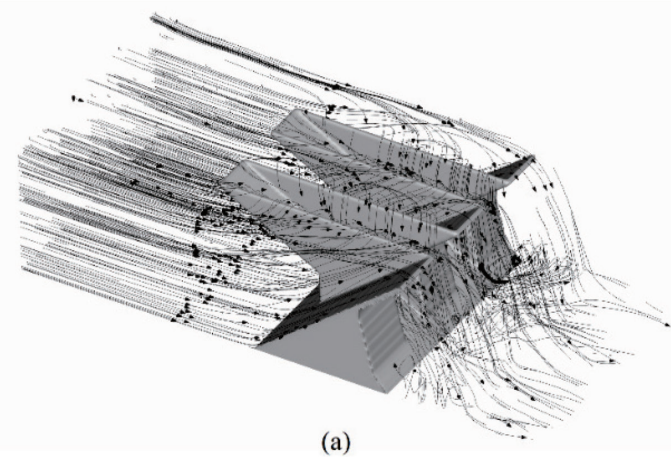

(a)

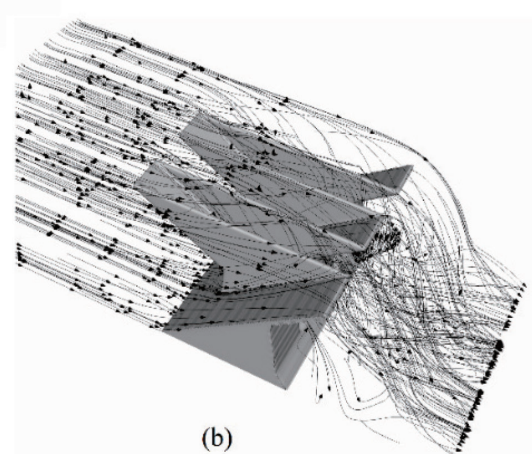

(b)

Figure 3: Three-dimensional streamlines for low and high heads of (a) $H / P=0.08$ and (b) $H / P=0.25$

\section{Main geometric parameters}

The total discharge over a PK weir is dependent on primary and secondary parameters. The primary parameters which have dominant effect on the discharge capacity are the crest length magnification ratio $L / W$, the weir height $P$ and the total head $H$ (including the velocity head). The ratio of inlet to outlet key width $\mathrm{Wi} / \mathrm{Wo}$, the height ratio $W u / P$, the upstream and downstream overhangs ratio $B i / B o$, the nose under upstream overhangs and the crest shape are only of secondary importance (Leite Ribeiro et al., 2012b). A statistical summary of key PK weir parameters from a data sample of 34 designed field-size situations throughout the world is presented in Figure 4 (Crookston et al., 2019).
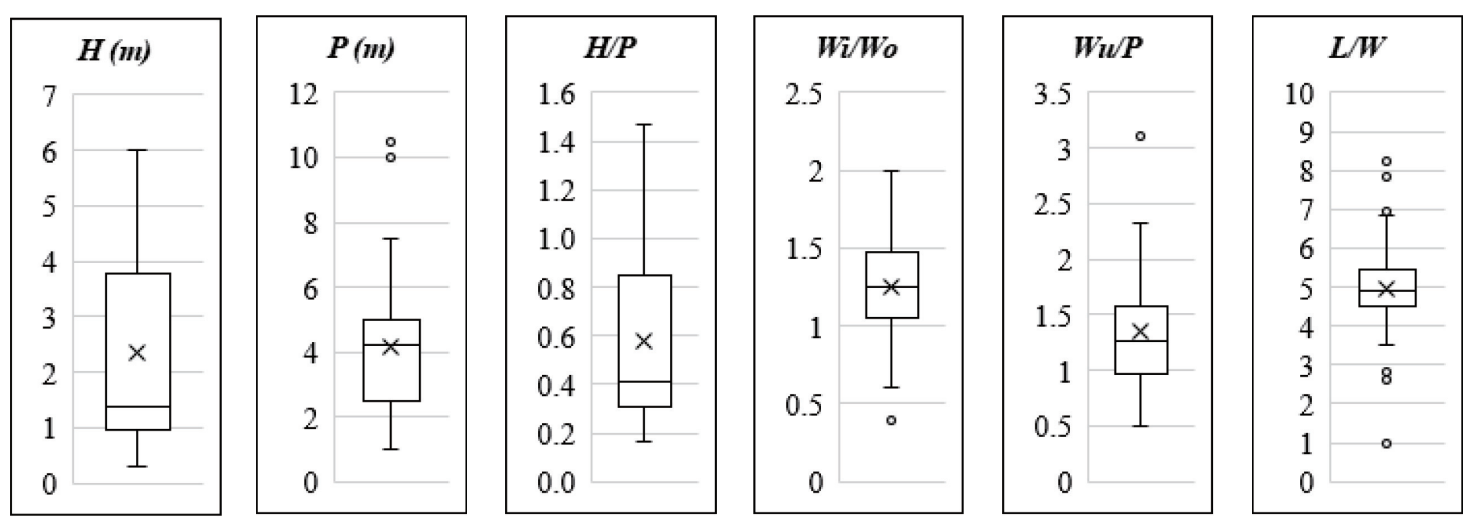

Figure 4: Distribution summary of geometric and hydraulic parameters from 34 PK weirs 
As an unregulated spillway which has been folded in nonlinear form, the purpose of using PK weir is to increase the total developed crest length for a given spillway width. Hence, the magnification ratio $L / W$ is the most fundamental parameter influencing the flow rate of a PK weir. This fraction shows how feasible a design is in using the available width $W$ to maximize the total crest length $L$. There is a proportional relationship between $L / W$ and discharge coefficient $C_{d}$. Indeed, there are differences of about $50 \%$ in discharge capacity between tests with $L / W=$ 7 and $L / W=3$ for a constant width occupied by the structure on the dam $W$ and low ratios $H / P$ (Leite Ribeiro et al., 2011). However, higher values of $L / W$ than 7 do not have an effect on $C_{d}$ (Kabiri-Samani and Javaheri, 2012). This finding is in agreement with the previous study of Ouamane and Lemperière (2006). Figure 4 indicates that most ratio lies between $L / W=4$ and 6. Laugier et al. (2017) recommended that value of 6 to 7 is the most efficient ratio from the perspective of hydraulic efficiency and economic feasibility.

In the case of a small upstream head $(H / P<0.2)$, the flow rate of the PK weir is comparatively large and the discharge enhancement ratio between PK WEIR and the traditional linear weir ( $r$ in equation 3 below) is higher than 3 , which indicates an obvious increase in the discharge efficiency. The PK weir discharge efficiency losses occur when increasing the hydraulic head. When $H / P>1.2$, the PK weir is only $1.2-1.3$ times more efficient than the linear weir (Guo et al., 2019). The efficiency losses can be elucidated by the formation of local submergence just downstream of the upstream overhang of the weir and the interference of the lateral nappes overflowing the adjacent weir walls of the inlet key. As a result, many projects were constructed in accordance with the range of $H / P$ of $0.2^{-}$ 0.8 (Figure 4).

As a direct result from research of Ouamane and Lempérière (2006), the discharge capacity of PK weir with $W i / W_{o}>1$ is higher than that of the symmetric configuration $\left(W i / W_{o}=1\right)$ and that with $W i / W_{o}<1$. Machiels (2012) described the flow in the inlet key as the "engine" of PK weir flow, whereas flow in the outlet key played a role as the "brake". With larger inlet keys the area of the inlet flow and the wetted perimeter increase, leading to reduced inlet velocities, contraction area and head loss. This refers to the fact that a wider inlet will advance flow into the weir. However, a wider inlet key coincides with a narrow outlet key which then restricts flow out of the weir and allows local submergence occurrence inside. A suitable balance must thus be struck between these two opposing effects. Lempérière and Jun (2005) and Hien et al. (2006) recommended $W_{i} / W_{o}=1.2$ as an optimal value producing a maximum discharge coefficient $C_{d}$. This finding is consistent with mean value of $W_{i} / W_{o}$ close to 1.25 in Figure 4 .

Regarding the overhangs lengths ratio $B_{i} / B_{o}$, the highest hydraulic efficiency of a "high" PK weir $\left(P / W_{u}>0.5\right)$ is reached for a value of 3 . For a "low" PK weir $\left(P / W_{u}<0.5\right)$, there is not rather difference as $B_{i} / B_{o}$ ratio ranges from 1 to 3 (Machiels et al., 2014).

\section{Analytical equations of PK weir discharge capacity}

As summarized by Schleiss (2011), because of the complexity of a PK weir geometry, three equations may be used to derive its discharge capacity.

The first equation uses the standard free flow weir equation involving a total head $H$ on the weir versus the transverse width $W$ as

$$
Q_{P K W}=2 / 3 C_{d W} W \sqrt{2 g H^{3}}
$$

with $Q_{P K W}$ as discharge, $H$ as total head, $W$ as total width of the weir, $g$ as the gravitational acceleration. The effect of weir is thus dependent on the discharge coefficient $C_{d W}$ (Ouamane and Lempérière, 2006). Completing 
determination of $C_{d W}$ is very difficult due to the complexity of the several factors influencing it (Lakshmana Rao S, 1975).

Relating to this approach, Kabiri-Samani and Javaheri (2012) have presented a discharge coefficient related to the width of the weir $C_{d W}$ for sharp-crested PK weirs with limitations $0.1 \leq H / P \leq 0.6 ; 2.5 \leq L / W \leq 7 ; 1 \leq B / P \leq 2.5$; $0.33 \leq W_{i} / W_{\mathrm{o}} \leq 1.22 ; 0 \leq B_{i} / B \leq 0.26 ; 0 \leq B_{o} / B \leq 0.26 ; H_{d} / H \leq 0.6$ as:

$$
C_{d W}=0.212\left(\frac{H}{P}\right)^{-0.675}\left(\frac{L}{W}\right)^{0.377}\left(\frac{W_{i}}{W_{o}}\right)^{0.426}\left(\frac{B}{P}\right)^{0.306} e^{\left(1.504 \frac{B_{o}}{B}+0.093 \frac{B_{i}}{B}\right)}+0.606
$$

The statistical analysis indicated that the coefficient of determination between the model of Kabiri-Samani and Javaheri (2012) and equation (1) combined with (2) is reported as $R^{2}=0.986$.

The second equation performed by comparison with the theoretical discharge capacity $Q_{s}$ of a linear sharpcrested weir of same width, considering the discharge enhancement ratio $r$ (Leite Ribeiro et al., 2012b):

$$
r=\frac{Q_{P K W}}{Q_{S}}=\frac{Q_{P K W}}{C_{S} W \sqrt{2 g} H^{3 / 2}}
$$

with $Q_{P K W}$ is the PK weir discharge. The discharge coefficient of the linear sharp crested weir $C_{s}$ can be assumed as constant with $C_{S}=0.42$ (Hager and Schleiss, 2009).

The values of $r$ were given as a function of primary and secondary parameters. The primary parameters with a dominant effect on the discharge capacity of a PK weir are the developed length $L$, the total transverse width $W$, the height of the inlet entrance measured from the PK weir crest (including possible parapet walls) $P_{i}$, and the total head $H$. The secondary parameters have a relatively small influence on discharge capacity, including the ratio of inlet to outlet key width $W i / W o$, the ratio of inlet to outlet height $P_{i} / P_{o}$, the relative overhang length $\left(B_{i}+B_{o}\right) / B$, and the relative parapet wall height $R_{o} / P_{o}$. Here, parapet walls are vertical extensions placed over the crest of a PK weir.

The measured $r$ collapsed with a trend line of normalized with $\delta$ as:

$$
r=1+0.24 \delta(w p b a)
$$

This equation was validated for half rounded crests with the limitations $0.1 \leq H / P \leq 2.8 ; 3.0 \leq L / W \leq 7.0 ; 1.5 \leq$ $B / P \leq 4.6 ; 0.50 \leq W_{i} / W_{o} \leq 2.0 ; 0.4 \leq\left(B_{o}+B i\right) / B \leq 0.8 ; 0.72 \leq P_{o} / P_{i} \leq 1.38 ; 0 \leq R_{o} / P_{o} \leq 0.22$ where:

$$
\delta=\left(\frac{(L-W) P_{i}}{W H}\right)^{0.9}
$$

and $w, p, b, a$ were found to be individual correction factors, expressing the influence of the secondary parameters:

$$
w=\left(\frac{W_{i}}{W_{o}}\right)^{0.05}
$$




$$
\begin{gathered}
p=\left(\frac{P_{o}}{P_{i}}\right)^{0.25} \\
b=\left(0.3+\frac{B_{o}+B_{i}}{B}\right)^{-0.5} \\
a=1+\left(\frac{R_{o}}{P_{o}}\right)^{2}
\end{gathered}
$$

Here, $r(\delta=0)=1$ (when $L=W$ or small $P_{i}$ combined with great $H$ ). All tests considered in Leite Ribeiro et al., (2012b) included a range of $1.2 \leq r \leq 5.3$ and the coefficient of determination between the measured data and equation (4) is $R^{2}=0.976$.

The third equation was derived from a detailed analytical formulation. Machiels et al. (2013) estimated the specific discharge $(q)$ for flat topped PK weirs as the sum of the specific discharges on the downstream $\left(q_{d}\right)$, the upstream $\left(q_{u}\right)$, and the lateral crests $\left(q_{s}\right)$ :

$$
q=\frac{Q_{P K W}}{W}=q_{u} \frac{W_{o}}{W_{u}}+q_{d} \frac{W_{i}}{W_{u}}+q_{s} \frac{2 B}{W_{u}}
$$

The three specific discharges can be estimated by using standard weir equations:

$$
\begin{gathered}
q_{u}=0.374\left(1+\frac{1}{1000 H+1.6}\right)\left[1+0.5\left(\frac{H}{H+P_{T}}\right)^{2}\right] \sqrt{2 g H^{3}} \\
q_{d}=0.445\left(1+\frac{1}{1000 H+1.6}\right)\left[1+0.5\left(\frac{H}{H+P}\right)^{2}\right] \sqrt{2 g H^{3}} \\
q_{s}=0.41\left(1+\frac{1}{833 H+1.6}\right)\left[1+0.5\left(\frac{0.833 H}{0.833 H+P_{e}}\right)^{2}\right]\left[\frac{P_{e}^{\alpha}+\beta}{\left(0.833 H+P_{e}\right)^{\alpha}+\beta}\right] K_{W_{i}} K_{W_{o}} \sqrt{2 g H^{3}}
\end{gathered}
$$

where $P_{T}=P+P_{d}$, with dam height below the PK weir $P_{d}$, the mean side wall height $P_{e}$ :

$$
P_{e}=\frac{B_{o}}{B} P_{T}+\left(1-\frac{B_{o}}{B}\right) \frac{P}{2}
$$

and, $\alpha$ and $\beta$ are parameters that characterize the influence of the inlet key slope $S_{i}$ on the side crest discharge efficiency:

$$
\begin{gathered}
\alpha=\frac{0.7}{S_{i}^{2}}-\frac{3.58}{S_{i}}+7.55 \\
\beta=0.029 e^{\left(\frac{-1.446}{S_{i}}\right)}
\end{gathered}
$$


Furthermore, $K_{W_{i}}$ describes the influence of the inlet key width $W_{i}$ on side crest discharge efficiency with $\gamma$ is an empirical expression:

$$
\begin{gathered}
K_{W_{i}}=1-\frac{\gamma}{\gamma+W_{i}^{2}} \\
\gamma=-0.0038 \frac{W_{i}}{W_{o}}+0.0055
\end{gathered}
$$

and $K_{W o}$ takes into account the side crest length decrease induced by the outlet key flow and the side nappe interference. It depends on $H / W_{o}$ :

$$
K_{W_{o}}=\left\{\begin{array}{lr}
1 & \text { if } \frac{H}{W_{o}} \leq \delta_{1} \\
\frac{2}{\left(\delta_{2}-\delta_{1}\right)^{3}}\left(\frac{H}{W_{o}}\right)^{3}-\frac{3\left(\delta_{2}+\delta_{1}\right)}{\left(\delta_{2}-\delta_{1}\right)^{3}}\left(\frac{H}{W_{o}}\right)^{2}+\frac{6 \delta_{2} \delta_{1}}{\left(\delta_{2}-\delta_{1}\right)^{3}}\left(\frac{H}{W_{o}}\right)+\frac{\delta_{2}^{2}\left(\delta_{2}-3 \delta_{1}\right)}{\left(\delta_{2}-\delta_{1}\right)^{3}} \\
\text { if } \delta_{1} \leq \frac{H}{W_{o}} \leq \delta_{2} & \text { if } \delta_{2} \leq \frac{H}{W_{o}}
\end{array}\right.
$$

The values of the two thresholds $\delta_{1}$ and $\delta_{2}$ are directly related to the outlet key slope $\left(S_{o}\right)$ :

$$
\begin{gathered}
\delta_{1}=-0.788 S_{o}^{-1.88}+5 \\
\delta_{2}=0.236 S_{o}^{-1.94}+5
\end{gathered}
$$

\section{Comparison}

Pfister and Schleiss (2013) presented a review of all three hydraulic design approaches for a symmetrical Atype PK weir prototype. The resulting discharge-head relationship curves are shown in Figure 5. In addition, the rating curve of a linear sharp-crested weir with same width and height is expressed, computing in respect of Vischer and Hager (1998). It was found that three studies basically estimate similar PK weir discharge for a certain head, but not identical results. In general, the second approach predicts the highest discharge capacity, and the analytical equation in the third approach provides the lowest values.

This difference is partially a result of the crest shape of the PK weir. In approaches conducted by Leite Ribeiro et al.(2012a) and Kabiri-Samani and Javaheri (2012), half-rounded crest and sharp-crested PK weir were used, respectively, while the analytical equation in Machiels et al.(2013) study used flat-topped shape of weir. Performance of flat-topped crest in terms of discharge capacity is still inferior to half-rounded crest and sharp-crested weir. The differences may also allude to the problem of not guaranteeing the suitable performance of the equations for predicting the PK weir discharge capacity outside its parameter limitations. According to Pfister et al., (2012), small discrepancies in this parameter range may lead to apparently incredible errors in the PK weir discharge calculation. Comparison of the analytical formulation with experimental data from different physical modeling studies, as well as real projects PK weirs configurations, shows a $15 \%$ accuracy in unit discharge prediction on a 
wide range of geometric parameters values (Machiels et al., 2013). Consequently, for a design process, the most appropriate PK weir hydraulic design formula shall be considered on the application limits of the capacity equations (Anderson and Tullis, 2012; Kabiri-Samani and Javaheri, 2012; Leite Ribeiro et al. 2012a, 2012b; Machiels et al., 2014). If possible, Erpicum et al., (2017a) recommended to consider applying different formulae in order to ensure a better predictive power.

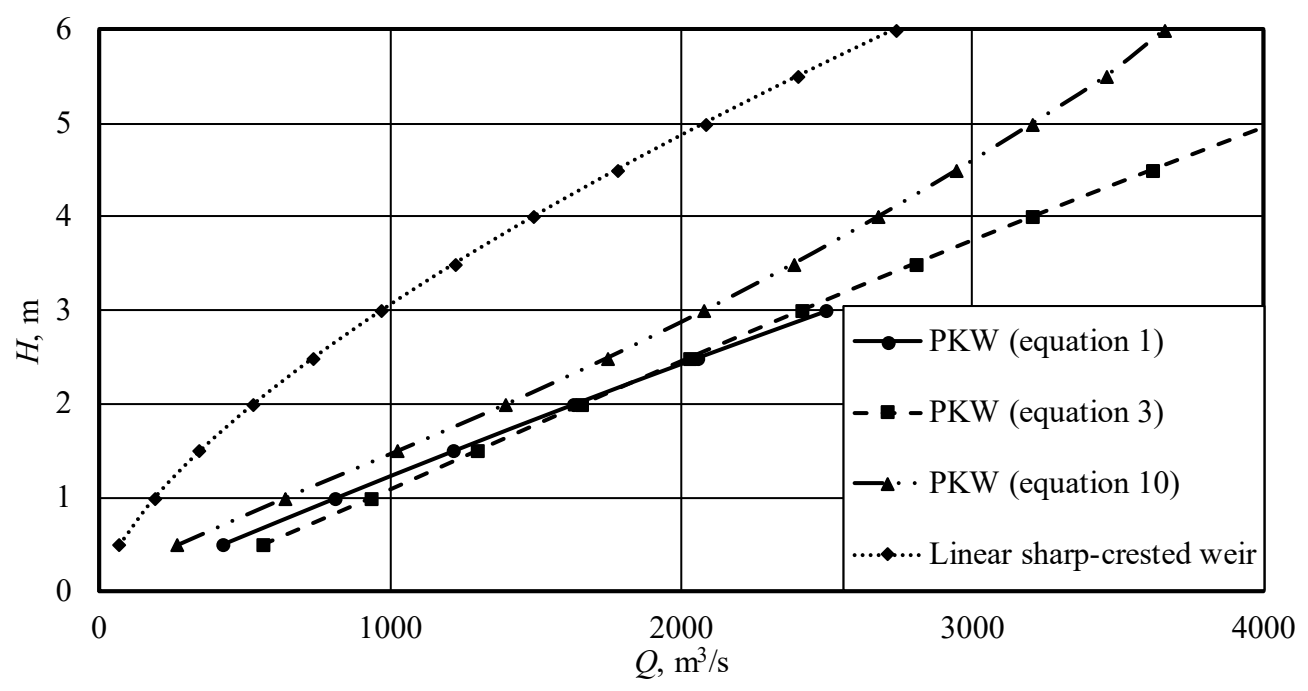

Figure 5: Comparison of rating curves for PK weir, linear sharp-crested weir

\section{Scale effects and discharge capacity prediction using mathematical models}

\subsection{Scale effects}

Scale effect occurs when a prototype hydraulic process is simulated at a laboratory scale due to dissatisfaction of similarity laws. It is suggested that scale effect in a PK weir physical model test could be efficiently reduced if both the geometric, kinematic and dynamic similitudes are satisfied simultaneously. This is often unachievable when a common fluid (e.g., water) is used for both the model and prototype. The viscosity and surface tension can affect the formation of free surface in experimental models. To avoid these effects, Erpicum et al. (2016) conclude that model-heads smaller than $0.03 \mathrm{~m}$ underestimate the discharge capacity at PK weirs, and that some $0.06 \mathrm{~m}$ are required to correctly reproduce the flow features in terms of nappe formation and jet geometry. However, according to Tullis et al. (2020), minimum heads to avoid scale effects varied with both model scale and actual weir size. Simply limiting the model geometric scale ratio is not sufficient when considering scale effects for PK weir model. The actual sizes of the prototype and model are indeed important consideration. The minimum dimensionless head $(H / P)$ below which scale effects occur generally decreases with increasing model size.

\subsection{Mathematical models}

Although specific physical models are considered to be an effective way of investigating fluid flows, simply conducting physical model tests prevents a comprehensive understanding of the hydraulic and discharge characteristics of PK weirs. Moreover, due to high cost of experiments, in recent years, researchers are encouraged to use mathematical methods for investigating the hydraulic characteristics of PK weirs. Mathematical modeling consists of computational fluid dynamic (CFD) methods and soft computing techniques. In the context of CFD the 
Navier-Stokes equations coupled with turbulence models using numerical methods are solved based on a multigrid algorithm. Recently, for using the CFD techniques number of available commercial software such as Fluent and Flow-3D and free open codes such as OpenFOAM have been employed. Using the CFD technique for simulating the flow over PK weirs was reported by many investigators (Crookston et al., 2018; Hu et al., 2018; Li et al., 2019; Oertel, 2016; Paxson and Savage, 2006). Soft computing approach, along with the CFD modeling, has become popular and has drawn research interest from investigators. Soft computing is not a single method, but it is a combination of several methods such as artificial neural networks (ANN's), Genetic Programming, Support Vector machine, Group Method of Data Handling, Adaptive Neuro Fuzzy Inference System (ANFIS). Predictions of the hydraulic characteristics of PK weir have been confirmed by Zounemat-Kermani and Mahdavi-Meymand (2019). General results indicated that all mathematical methods can simulate the PK weir discharge more accurately than empirical relations. However, it is fair to say that mathematical method has not yet emerged as a reliable means for PK weir design. The experts recognize the need to verify and validate the code. The errors of the mathematical method can be minimized by comparing the results to those of experiments which are always the final proof.

\section{Conclusions}

PK weir is a complex structure involving a large number of geometric parameters and an interaction of flows over up/downstream crest and lateral crest of the keys. This review paper is a result of a demand for a comprehensive coverage on the hydraulic behavior of PK weir. The flow over a PK weir is the cumulative of three different types of overflow: flow over the inlet key downstream crest, flow over the outlet key upstream crest and flow over the lateral wall. The downstream crest of the inlet is always supplied by the current in front of the key. Meanwhile, only the surface current comes into the outlet. The lateral discharge capacity decreases considerably when upstream head increases. The flow characteristics over a PK weir are dependent on primary and secondary geometrical parameters, which increase difficulty level of discharge capacity prediction. Three general design equations were proposed in recent years. Summary of analysis results illustrated that there is a fine agreement between three equations, however discrepancies still exist. Besides that, researchers are encouraged to use mathematical models to calculate the PK weir discharge. Although, recent published studies have proved the accuracy of the numerical solution, this approach still need to be further investigated in the future.

\section{REFERENCES}

Ackers JB (2013) Raising of the bellmouth spillway at Black Esk reservoir using Piano Key Weirs. Labyrinth and Piano Key Weirs II - PKW 2013: 235-242.

Anderson RM and Tullis BP (2012) Piano key weir: Reservoir versus channel application. Journal of Irrigation and Drainage Engineering, 138(8): 773-776.

Barcouda M, Laugier F, Cazaillet O, Odeyer C, Cochet P, Jones BA, Lacroix S and Vigny JP (2006) Cost effective increase in storage and safety of most existing dams using fusegates or P.K.Weirs. Proceeding of the 22nd ICOLD Congress.

Bieri M, Ribeiro ML and Boillat JL (2009) Rehabilatation de la Capacite D'evacuation des Crues-Integration de PK-weirs sur des Barrages Existants (Rehabilitation of discharge capacity: Integration of PK weirs on existing dams). Proc., Colloque CFBR-SHF, Dimensionnement et Fonctionnement Des Évacuateurs de Crues: 20-21.

Blanc P and Lempérière F (2001) Labyrinth spillways have a promising future. International Journal on Hydropower and Dams: 8(4): 129-131.

Boillat JL, Leite Ribeiro M, Pralong J, Erpicum S and Archambeau P (2011) Creation of a PKW database: Discussion. Labyrinth and Piano Key Weirs - PKW 2011: 279-280.

Cicero G and Delisle J (2013) Effects of the crest shape on discharge efficiency of a type A Piano Key weir. Labyrinth and Piano Key Weir II - PKW 2013: 41-48. 
Crookston BM, Anderson RM and Tullis BP (2018) Free-flow discharge estimation method for Piano Key weir geometries. Journal of Hydro-Environment Research, 19: 160-167.

Crookston BM, Crowley L and Pfister M (2016) Piano key weir for enlargement of the West Fork of Eno River Reservoir. 6th International Symposium on Hydraulic Structures: Hydraulic Structures and Water System Management, ISHS 2016, 3300628160: 430-439.

Crookston BM, Erpicum S, Tullis BP and Laugier F (2019) Hydraulics of Labyrinth and Piano Key Weirs: 100 Years of prototype structures, advancements, and future research needs. Journal of Hydraulic Engineering, 145(12): 1-7.

Denys F, Basson G and Strasheim J (2017) Fluid structure interaction of piano key weirs. Proc., Labyrinth and Piano Key Weirs III PKW 2017: 119-126.

Eichenberger P (2013) The first commercial Piano Key Weir in Switzerland. Labyrinth and Piano Key Weir II- PKW 2013, $227-234$.

Erpicum S, Archambeau P, Dewals B and Pirotton M (2017a) Hydraulics of Piano Key Weirs: A review. Labyrinth and Piano Key Weirs III- PKW 2017: 27-36.

Erpicum S, Laugier F, Ho Ta Khanh M and Pfister M (2017b) Labyrinth and Piano Key Weirs III -PKW 2017. CRC Press.

Erpicum S, Laugier F, Pfister M, Pirotton M, Cicero GM and Schleiss AJ (2013) Labyrinth and Piano Key Weirs II - PKW 2013.

Erpicum S, Laugier F, Boillat JL, Pirotton M, Reverchon B and Schleiss AJ (2011) Labyrinth and Piano Key Weirs - PKW 2011.

Erpicum S, Machiels O, Archambeau P, Dewals B and Pirotton M (2010) 1D numerical approach to model the flow over a piano key weir (PKW). SimHydro 2010: Hydraulic Modeling and Uncertainty, July.

Erpicum S, Tullis BP, Lodomez M, Archambeau P, Dewals BJ and Pirotton M (2016) Scale effects in physical piano key weirs models. Journal of Hydraulic Research, 54(6): 692-698.

Guo X, Liu Z, Wang T, Fu H, Li J, Xia Q and Guo Y (2019) Discharge capacity evaluation and hydraulic design of a piano key weir. Water Science and Technology: Water Supply, 19(3): 871-878.

Hager WH and Schleiss AJ (2009) Constructions hydrauliques: écoulements stationnaires. PU POLYTECHNIQU.

Hien TC, Son HT and Ho Ta Khanh M (2006) Results of some piano key weirs hydraulic model tests in Vietnam. Proceeding of the 22nd ICOLD Congress.

Ho Ta Khanh M (2017) History and development of Piano Key Weirs in Vietnam from 2004 to 2016. Proc., Labyrinth and Piano Key Weirs III: 3rd Int. Workshop on Labyrinth Piano Key Weirs (PKW 2017): 3-16.

Ho Ta Khanh M, Chi Hien T and Sy Quat D (2012) Study and construction of PK Weirs in Vietnam (2004 to 2011). Fourth International Conference on Water Resources and Renewable Energy Development in Asia, 95: 3-6.

Ho Ta Khanh M, Hien T and Hai N (2011) Main results of the P.K weir under design and construction in Vietnam. Labyrinth and Piano Key Weirs - PKW 2011: 191-198.

Hu H, Qian Z, Yang W, Hou D and Du L (2018) Numerical study of characteristics and discharge capacity of piano key weirs. Flow Measurement and Instrumentation, 62(May): 27-32.

Jayatillake HM and Perera KT (2013) Design of a Piano-Key Weir for Giritale dam spillway in Sri Lanka. Lybitinth and Piano Key Weir II - PKW 2013: 151-158.

Kabiri-Samani A and Javaheri A (2012) Discharge coefficients for free and submerged flow over Piano Key weirs. Journal of Hydraulic Research, 50(1): 114-120.

Lakshmana Rao SN (1975) Theory of weirs. In V. Te Chow (Ed.), Advances in Hydroscience: 309-406.

Laugier F (2007) Design and construction of the first Piano Key Weirs spillway at the Goulours dam. Hypdopower and Dams, 14(5): 94-101.

Laugier F, Lochu A, Gille C, Ribeiro ML and Boillat JL (2009) Design and construction of a labyrinth PKW spillway at Saint-Marc dam, France. The International Journal of Hydpropower and Dams, 6(5): 100-107.

Laugier F, Vermeulen J and Blancher B (2017) Overview of design and construction of 11 piano key weir spillways developed in France by EDF from 2003 to 2016. Labyrinth and Piano Key Weir III - PKW 2017: 37-51.

Leite Ribeiro M, Bieri M, Boillat JL, Schleiss AJ, Singhal G and Sharma N (2012a) Discharge capacity of piano key weirs. Journal of Hydraulic Engineering, 138(2): 199-203.

Leite Ribeiro M, Boillat JL, Schleiss AJ, Le Doucen O and Laugier F (2011) Experimental parametric study for hydraulic design of PKWs. Labyrinth and Piano Key Weirs - Proceedings of the International Conference on Labyrinth and Piano Key Weirs, PKW 2011: 183-190. 
Leite Ribeiro M, Pfister M, Schleiss AJ and Boillat JL (2012b) Hydraulic design of a-type piano key weirs. Journal of Hydraulic Research, 50(4): 400-408.

Lempérière F (2011) New labyrinth weirs triple the spillways discharge. Water and Energy International, 68(11): 77-78.

Lempérière F and Jun G (2005) Low cost increase of dam storage and flood mitigation: the Piano key weir. International Commission on Irrigation and Drainage - Nineteen Congress.

Lempérière F and Ouamane A (2003) The Piano Keys weir: A new cost-effective solution for spillways. International Journal on Hydropower and Dams, 10(5): 144-149.

Li G, Li S and Hu Y (2019) The effect of the inlet/outlet width ratio on the discharge of piano key weirs. Journal of Hydraulic Research, 1686.

Machiels O, Dewals B, Archambeau P, Pirotton M and Erpicum S (2013) An anlytical approach for Piano Key weir hydraulic design. Labyrinth and Piano Key Weirs II - PKW 2013: 131-138.

Machiels O (2012) Experimental study of the hydraulic behaviour of Piano Key Weirs (Issue June).

Machiels O, Erpicum S, Dewals BJ, Archambeau P and Pirotton M (2011). Experimental observation of flow characteristics over a Piano Key Weir. Journal of Hydraulic Research, 49(3): 359-366.

Machiels O, Pirotton M, Pierre A, Dewals B and Erpicum S (2014) Experimental parametric study and design of Piano Key Weirs. Journal of Hydraulic Research, 52(3): 326-335.

Mei W and Xie SP (2016) Intensification of landfalling typhoons over the northwest Pacific since the late 1970s. Nature Geoscience, 9(10): 753-757.

Oertel M (2016) Sensitivity analysis for discharge coefficients of Piano Key Weirs. 6th International Symposium on Hydraulic Structures: Hydraulic Structures and Water System Management: 540-548.

Ouamane A and Lempérière F (2006) Design of a new economic shape of weir. Proceedings of the International Symposium on Dams in the Societies of the 21 st Century, ICOLD-SPANCOLD - Dams and Reservoirs, Societies and Environment in the 21st Century, 1(June 2006): 463-470.

Paxson G, Tullis B and Hertel D (2013) Comparison of Piano Key Weirs with labyrinth and gated spillways: Hydraulics, cost, constructability and operations. Labyrinth and Piano Key Weirs II - PKW 2013: 123-130.

Paxson Greg and Savage B (2006) Labyrinth Spillways: Comparison of Two Popular U.S.A. Design Methods and Consideration of Non-Standard Approach Conditions and Geometries. International Junior Researcher and E Ngineer Workshop on Hydraulic Structures, 1968: 37-46.

Pfister M, Erpicum S, Machiel O, Schleiss A and Pirotton M (2012) Discharge coefficient for free and submerged flow over Piano Key Weirs - Discussion. Journal of Hydraulic Research, 50(6): 642-645.

Pfister M and Schleiss AJ (2013) Comparison of hydraulic design equations for A-Type Piano Key Weirs. Proceedings of the International Conference on Water Storage and Hydropower Development for Africa (AFRICA 2013), April: 1-8.

Pralong J, Montarros F, Blancher B and Laugier F (2011) A sensitivity analysis of piano key weirs geometrical parameters based on 3D numerical modeling. Labyrinth and Piano Key Weirs - Proceedings of the International Conference on Labyrinth and Piano Key Weirs, PKW 2011: 133-139.

Schleiss AJ (2011) From labyrinth to Piano Key Weirs - A historical review. Labyrinth and Piano Key Weirs - PKW 2011 : 3-15.

Trenberth K (2011) Changes in precipitation with climate change. Climate Research, 47(1): 123-138.

Tullis BP, Crookston BM and Young N (2020) Scale effects in free-flow nonlinear weir head-discharge relationships. Journal of Hydraulic Engineering, 146(2): 1-9.

Vischer DL and Hager WH (1998) Dam Hydraulics (1st ed.). Wiley.

Zounemat-Kermani M and Mahdavi-Meymand A (2019) Hybrid meta-heuristics artificial intelligence models in simulating discharge passing the piano key weirs. Journal of Hydrology, 569(November): 12-21. 